Diabetologia (1994) 37: 308-312

\title{
Salt-sensitivity is associated with a hyperinsulinaemic and hyperglycaemic response to atrial natriuretic peptide infusion in human essential hypertension
}

\author{
C. Ferri ${ }^{1}$, C. Bellini ${ }^{1}$, G.Desideri ${ }^{1}$, L.Di Francesco ${ }^{1}$, G. De Mattia ${ }^{1}$, A. Santucci ${ }^{2}$, F. Balsano ${ }^{1}$ \\ ${ }^{1}$ University of Rome "La Sapienza", Institute of I Clinica Medica, Andrea Cesalpino Foundation, Rome, Italy \\ ${ }^{2}$ University of L'Aquila, Department of Internal Medicine, L'Aquila, Italy
}

Summary To evaluate the influence of salt-sensitivity on the plasma insulin and glucose response to infusion of ANP, we studied 22 men with essential hypertension, who were between 40 and 60 years old. After 1 month under normal $\mathrm{Na}^{+}$intake $\left(120 \mathrm{mmol} \mathrm{Na}{ }^{+}\right.$per day $)$, patients were randomly assigned to receive either ANP $\left(0.04 \mu \mathrm{g} \cdot \mathrm{kg}^{-1} \cdot \mathrm{min}^{-1}\right)(n=15)$ or vehicle $(50 \mathrm{ml}$ saline $)$ $(n=7)$ over a 60 -min period, while in the supine position. Plasma insulin and glucose were measured at time $-60,0,20,40,60,120,180,240 \mathrm{~min}$. Ten days after ANP infusion, blood pressure sensitivity to changes in dietary salt intake was assessed according to a randomized double-blind crossover protocol. Patients were classified into two groups either salt-sensitive $(n=8)$ or salt-resistant $(n=7)$. Our results showed that plasma insulin and glucose did not change during ANP infusion in both groups. However, both plasma insulin (from
$75.6 \pm 45.1 \mathrm{pmol} / \mathrm{l}$ at $60 \mathrm{~min}$ to $121.2 \pm 48.6 \mathrm{pmol} / \mathrm{l}$ at $240 \mathrm{~min}, p<0.05$ vs time 0 ) and glucose levels (from $4.86 \pm 0.73 \mathrm{mmol} / 1$ at $60 \mathrm{~min}$ to $6.56 \pm 1.03 \mathrm{mmol} / \mathrm{l}$ at $240 \mathrm{~min}, p<0.01$ vs time 0 ) rose after discontinuation of ANP in salt-sensitive patients, but did not change at all in salt-resistant patients. In conclusion, this randomized vehicle-controlled study demonstrates that plasma insulin and glucose levels increase in salt-sensitive hypertensive patients after the infusion of ANP. The increase of plasma insulin levels observed after ANP discontinuation, if occurring under physiologic conditions, could influence the blood pressure sensitivity to dietary $\mathrm{Na}^{+}$intake.

Key words Hypertension, atrial natriuretic peptide, insulin, salt-sensitivity, kidney. [Diabetologia (1994) 37: 308-312]
Controversial data have indicated that ANP may enhance [1] or inhibit [2] glucose-stimulated insulin secretion from rat pancreas. In humans, a significant increase of plasma insulin levels has been reported during the infusion of high doses of ANP [3, 4], but an acute increase in circulating ANP within the physiological range was not associated with changes in insulin levels [5, 6]. Moreover, we have previously shown in essential hypertensive patients [7] that plas-

Received: 29 April 1993

and in final revised form: 12 October 1993

Corresponding author: Dr. C. Ferri, University of Rome "La Sapienza", Institute of I Clinica Medica, Andrea Cesalpino Foundation, I-00161 Rome, Italy

Abbrevations: ANP, Atrial natriuretic peptide; NIDDM, non-insulin dependent diabetes mellitus. ma insulin and glucose levels did not change during ANP infusion, while they increased after its discontinuation.

With regard to possible correlations among insulin, ANP and blood pressure sensitivity to dietary salt intake, recent findings have shown raised levels of ANP in conditions which can be associated with both raised circulating insulin levels and salt-sensitivity, such as hypertension and NIDDM [7-9]. Furthermore, a hyperglycaemic and hyperinsulinaemic response to oral glucose load has been described in salt-sensitive lean normotensive subjects [10]. However, although insulin levels seem to be partly related to sodium intake [10], the impact of salt-sensitivity on insulin and glucose response to ANP infusion is not known.

The aim of this study was to clarify the effect of ANP infusion on plasma insulin and glucose levels in nonobese euglycaemic hypertensive patients, divided into either salt-sensitive or salt-resistant patients. 


\section{Subjects and methods}

\section{Patients}

We asked 35 essential hypertensive men to participate in the study. The study protocol was approved by the Ethics Committee of the Andrea Cesalpino Foundation. All patients gave their informed consent and took no medication for 1 month before starting the study. Hypertension was mild to moderate, and the following selection criteria were used: age between 40 and 60 years, body mass index more than 19 and less than $26 \mathrm{~kg} / \mathrm{m}^{2}$, diastolic blood pressure between $95 \mathrm{~mm} \mathrm{Hg}$ and $114 \mathrm{~mm} \mathrm{Hg}$, serum creatinine less than $100 \mu \mathrm{mol} / 1$, normal ${ }^{99 \mathrm{~m}} \mathrm{Tc}-\mathrm{DTPA}$ and $\left.{ }^{[31} \mathrm{I}\right] \mathrm{o}$-iodohippurate scintirenographies, microalbuminuria less than $20 \mu \mathrm{g} / \mathrm{min}$, normal autonomic function. None of the patients had cardiac hypertrophy, left ventricular and/or atrial dysfunction as evaluated on the basis of clinical and ultrasound studies. Patients who smoked were excluded from the study, as were those who drank more than $10 \mathrm{~g}$ alcohol per day. Secondary forms of hypertension were excluded by clinical and laboratory assessments. The absence of impaired glucose tolerance was confirmed by the following criteria: fasting glucose levels less than $6.7 \mathrm{mmol} / \mathrm{l}$, fructosamine levels less than $280 \mu \mathrm{mol} / \mathrm{l}$, absence of glycosuria, normal plasma glucose response to oral administered glucose $(75 \mathrm{~g})$. Patients who showed fasting insulin levels more than $110 \mathrm{pmol} / \mathrm{l}$ or abnormal insulin response to oral glucose load $(75 \mathrm{~g})$ were excluded from the study.

During this phase, all patients were on a normal $\mathrm{Na}^{+}$intake $\left(120 \mathrm{mmol} \mathrm{NaCl}\right.$ per day for 2 weeks). The normal $\mathrm{Na}^{+}$regimen was achieved by a daily supplement of 4 capsules (each containing $25 \mathrm{mmol} \mathrm{NaCl}$ ) added to a normocaloric diet containing $20 \mathrm{mmol} \mathrm{Na}^{+}$and $60 \mathrm{mmol} \mathrm{K}^{+}$per day. Compliance was assessed by measuring daily the 24 -h urinary sodium and chloride excretion, and was defined as a sodium and chloride excretion greater than $80 \mathrm{mmol} /$ day and less than $130 \mathrm{mmol} /$ day. Two patients were considered not compliant and excluded from the study.

\section{ANPinfusion}

After the 2-week period under normal sodium intake, five patients had a supine diastolic blood pressure less than $95 \mathrm{~mm} \mathrm{Hg}$ and were removed from the study. The remaining patients $(n=28)$ were hospitalized and then randomly assigned to receive either ANP (99-126, Peninsula Laboratories, Belmont, Calif., USA) or its vehicle ( $50 \mathrm{ml}$ isotonic saline) in a double blind manner.

On the morning of the study, patients voided urine at 07.00 hours. After $1 \mathrm{~h}$ in the supine position, an intravenous catheter was inserted into a forearm vein for infusion of either ANP or isotonic saline. A heparin-lock butterfly system for blood sampling was inserted in a vein on the other forearm. Infusion rates were controlled by a peristaltic pump (Abbot/Shaw Life Care Pump, Chicago, Ill., USA). ANP was infused at a rate adjusted to deliver $0.04 \mu \mathrm{g} \cdot \mathrm{kg}^{-1} \cdot \mathrm{min}^{-1}$ for $60 \mathrm{~min}$. In both the placebo and the ANP groups the total amount of isotonic saline infused was $50 \mathrm{ml}$. Blood samples were drawn at $-60,0,20,40,60,120,180$, 240 min for the determination of plasma ANP, insulin and glucose and of serum electrolytes $\left(\mathrm{Na}^{+}, \mathrm{K}^{+}\right)$. Urine was collected every hour, from -60 min to $240 \mathrm{~min}$. Plasma glucose, serum $\mathrm{Na}^{+}$ and $\mathrm{K}^{+}$were evaluated by standard laboratory methods immediately after blood collection. Plasma samples for ANP and insulin assays were frozen at $-80^{\circ} \mathrm{C}$. The assays were performed no later than 1 week after blood collection. Plasma insulin levels were assayed by a commercial radioimmunoassay kit (AresSerono, Milan, Italy). Plasma ANP was measured as described elsewhere [11], by a commercially available human-ANP (99-
126) radioimmunoassay (Peninsula Laboratories). Inter- and intra-assay variations were less than $10 \%$. Urinary $\mathrm{Na}^{+}$and $\mathrm{K}^{+}$ excretions were evaluated by standard laboratory methods.

During the infusion, blood pressure and heart rate were measured at 5-min intervals by an automatic sphygmomanometer (Nippon Colin, Komai, Japan). Mean blood pressure was calculated according to the well-known formula: diastolic $+\frac{\text { (systolic }- \text { diastolic })}{3}=$ mean blood pressure.

\section{Determination of salt-sensitivity}

This part of the study was conducted by a second group of researchers, who operated unaware of the remaining part of the protocol.

At the end of either ANP or vehicle administration, patients continued the normal sodium diet for a further 10-day period. After this period, the daily supplement of 4 capsules containing sodium chloride ( $25 \mathrm{mmol} \mathrm{Na}^{+} /$capsule), given to each patient starting from the beginning of the study (see above), were substituted, according to a randomized double-blind crossover design, with identical capsules containing either a different amount of sodium chloride ( $50 \mathrm{mmol} \mathrm{Na}^{+} /$capsule) or placebo (dextrose). By the use of this protocol each patient was given both a high ( $220 \mathrm{mmol} \mathrm{Na}^{+}$per day) and a low $\left(20 \mathrm{mmol} \mathrm{Na}^{+}\right.$per day) $\mathrm{NaCl}$ intake, in a complete double-blind manner. Each $\mathrm{NaCl}$ diet (i.e. low and high $\mathrm{NaCl}$ diet) was followed for 10 days.

Throughout the study, compliance was assessed by measuring the daily $24-\mathrm{h}$ sodium excretion by standard laboratory methods. Patients were considered compliant when 24 -h sodium excretion was more than $200 \mathrm{mmol}$ during the high sodium intake and less than $40 \mathrm{mmol}$ during the low sodium intake. Three patients were considered not compliant, and the salt-sensitivity assessment was completed in 25 patients.

Every morning during the salt-sensitivity assessment, blood pressure was measured four times, at 5-min intervals, using a Riva-Rocci sphygmomanometer (Zenith, Rome, Italy) on waking, after a 9-h sleep (08.00 hours). The average of the last three measurements was used. Blood pressure was taken by researchers who were unaware of the patient's $\mathrm{NaCl}$ intake.

Salt-sensitivity was defined as a significant drop in diastolic blood pressure of $10 \mathrm{~mm} \mathrm{Hg}$ or more on day 10 of low salt intake, plus a significant increase of $10 \mathrm{~mm} \mathrm{Hg}$ or more on day $10 \mathrm{of} \mathrm{high}$ salt intake, considering as baseline the blood pressure measurement on day 10 of normal sodium intake. Salt-resistance was defined as the absence of blood pressure changes (greater than $10 \mathrm{~mm} \mathrm{Hg}$ ) after low or high salt intake. Some patients $(n=3)$ had inconsistent blood pressure responses (i.e. diastolic blood pressure changes greater than $10 \mathrm{~mm} \mathrm{Hg}$ occurred only during the low or the high sodium intake) and were not classified. These patients are not considered in the following results section.

\section{Statistical analysis}

The statistical evaluation was performed by a PC IBM PS30 (Armonk, NY, USA), by using the statistical software Primer (McGraw-Hill, New York, NY, USA). Statistical analysis was performed by the analysis of variance test, followed by the Bonferroni and the Student-Newman-Keuls' test. Variable comparisons between groups were performed by the unpaired Student's $t$ test and one way analysis of variance with Bonferroni test. Linear regression and correlation were used to evaluate relationship between two variables. Statistical significance was considered for $p$ values less than 0.05 . All results are given as mean $\pm S D$. 
Table 1. Physical, plasma and urinary variables in salt-sensitive $(n=8)$ and salt-resistant $(n=7)$ essential hypertensive men under normal-salt (120 mmol/day), low-salt (20 mmol/day), and high-salt ( $220 \mathrm{mmol} /$ day $)$ diet. Sodium was given as sodium chloride

\begin{tabular}{|c|c|c|c|c|c|c|}
\hline & \multicolumn{3}{|l|}{ Salt-sensitive } & \multicolumn{3}{|l|}{ Salt-resistant } \\
\hline & Normal & Low & High & Normal & Low & High \\
\hline $\begin{array}{l}\text { Systolic blood pressure } \\
\text { (mm Hg) }\end{array}$ & $153.5 \pm 11.2$ & $146.6 \pm 8.8^{\mathrm{b}}$ & $161.4 \pm 12.6^{\mathrm{b}, \mathrm{c}}$ & $150.5 \pm 10.8$ & $152.4 \pm 8.9$ & $150.3 \pm 11.2$ \\
\hline $\begin{array}{l}\text { Diastolic blood pressure } \\
(\mathrm{mm} \mathrm{Hg})\end{array}$ & $101.5 \pm 3.0$ & $89.1 \pm 2.5^{\mathrm{b}}$ & $115.4 \pm 3.5^{\mathrm{b}, \mathrm{c}}$ & $100.5 \pm 2.5$ & $99.0 \pm 3.5$ & $100.5 \pm 2.5$ \\
\hline Heart rate (beats/min) & $72.4 \pm 6.7$ & $71.5 \pm 5.9$ & $74.3 \pm 5.4$ & $69.7 \pm 5.9$ & $70.3 \pm 4.7$ & $72.3 \pm 3.8$ \\
\hline Weight (kg) & $72.3 \pm 2.5$ & $70.8 \pm 1.8^{\mathrm{a}}$ & $73.8 \pm 2.0^{\mathrm{a}, \mathrm{d}}$ & $74.3 \pm 1.6$ & $73.9 \pm 1.8$ & $74.6 \pm 1.9$ \\
\hline \multicolumn{7}{|l|}{ Plasma variables } \\
\hline Sodium $(\mathrm{mmol} / \mathrm{l})$ & $135.1 \pm 1.1$ & $134.2 \pm 2.7$ & $136.2 \pm 3.4$ & $134.5 \pm 0.9$ & $133.2 \pm 1.3$ & $136.3 \pm 2.3$ \\
\hline Potassium $(\mathrm{mmol} / \mathrm{l})$ & $3.9 \pm 0.1$ & $3.8 \pm 0.1$ & $4.0 \pm 0.1$ & $4.0 \pm 0.1$ & $4.0 \pm 0.1$ & $3.9 \pm 0.2$ \\
\hline Glucose (mmol/l) & $4.15 \pm 0.5$ & $4.02 \pm 0.5$ & $4.26 \pm 0.5$ & $4.21 \pm 0.6$ & $4.24 \pm 0.4$ & $4.23 \pm 0.6$ \\
\hline Insulin (pmol/l) & $54.6 \pm 21.6$ & $60.6 \pm 16.2$ & $54.0 \pm 18.6$ & $60.6 \pm 15.6$ & $58.8 \pm 20.4$ & $55.2 \pm 15.6$ \\
\hline \multicolumn{7}{|l|}{ Urine variables } \\
\hline Volume (ml/24 h) & $1856 \pm 200$ & $1722 \pm 160$ & $2012 \pm 330$ & $1762 \pm 236$ & $1683 \pm 322$ & $1990 \pm 245$ \\
\hline Sodium (mmol/24 h) & $105.2 \pm 7.6$ & $21.0 \pm 5.2^{\mathrm{b}}$ & $216.4 \pm 4.5^{\mathrm{b}, \mathrm{e}}$ & $103.2 \pm 5.1$ & $18.1 \pm 2.7^{b}$ & $211.4 \pm 10.3^{\mathrm{b}, \mathrm{e}}$ \\
\hline Chloride (mmol/24h) & $103.3 \pm 6.9$ & $19.2 \pm 6.4^{b}$ & $209.9 \pm 5.8^{\mathrm{b}, \mathrm{e}}$ & $105.7 \pm 4.2$ & $16.2 \pm 3.7^{\mathrm{b}}$ & $218.8 \pm 6.7^{\mathrm{b}, \mathrm{e}}$ \\
\hline
\end{tabular}

${ }^{\mathrm{a}} p<0.05,{ }^{\mathrm{b}} p<0.001$ vs normal salt;

${ }^{\mathrm{c}} p<0.05,{ }^{\mathrm{d}} p<0.01,{ }^{\mathrm{e}} p<0.0001$ high vs low salt

\section{Results}

Salt-sensitivity. Fifteen patients who received ANP (mean age $45.0 \pm 4.5$ years) (ANP group) and seven patients who received isotonic saline (mean age $47.7 \pm$ 4.9 years) (placebo group) completed the study. In the first group, eight patients (mean age $45.3 \pm 5.3$ years) proved to be salt-sensitive and seven (mean age $44.5 \pm$ 3.6 years) salt-resistant (Table 1). Baseline levels of plasma ANP and insulin were significantly correlated in salt-sensitive $(p<0.01)$ but not in salt-resistant patients.

ANP infusion. Plasma ANP levels were $9.9 \pm 1.9 \mathrm{fmol} /$ $\mathrm{ml}$ at time 0. After 20,40 and $60 \mathrm{~min}$ of ANP infusion, plasma ANP concentrations rose to $40.3 \pm 3.4 \mathrm{fmol} / \mathrm{ml}$ $(p<0.002), 53.4 \pm 4.6 \mathrm{fmol} / \mathrm{ml}(p<0.0001)$ and $52.2 \pm$ $3.5 \mathrm{fmol} / \mathrm{ml}(p<0.0001)$, respectively. After ANP discontinuation, plasma ANP returned to baseline levels, being $10.8 \pm 4.7 \mathrm{fmol} / \mathrm{ml}, 8.0 \pm 2.3 \mathrm{fmol} / \mathrm{ml}$ and $9.6 \pm$ $2.7 \mathrm{fmol} / \mathrm{ml}$ at 120,180 and $240 \mathrm{~min}$, respectively.

Blood pressure and heart rate. In the ANP group saltsensitive patients showed a significant decrease of mean blood pressure (from $125 \pm 5 \mathrm{~mm} \mathrm{Hg}$ at time 0 to $110 \pm$ $4 \mathrm{~mm} \mathrm{Hg}$ at $20 \mathrm{~min}, p<0.05 ; 105 \pm 3 \mathrm{~mm} \mathrm{Hg}$ at $40 \mathrm{~min}$, $p<0.05 ; 101 \pm 4 \mathrm{~mm} \mathrm{Hg}$ at $60 \mathrm{~min}, p<0.04 ; 111 \pm 4 \mathrm{~mm}$ $\mathrm{Hg}$ at $120 \mathrm{~min}, p<0.05$ ), which returned to basal values

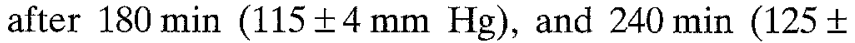
$5 \mathrm{~mm} \mathrm{Hg}$ ). After the end of ANP infusion, heart rate showed a significant increase from $71 \pm 5$ beats $/ \mathrm{min}$ at time 0 and $73 \pm 8$ beats/min at $60 \mathrm{~min}$ to $99 \pm 12$ beats/ $\mathrm{min}$ at $75 \mathrm{~min}, p<0.03 ; 97 \pm 10$ beats $/ \mathrm{min}$ at $90 \mathrm{~min}$, $p<0.05$; and $68 \pm 9$ beats $/ \mathrm{min}$ at $120 \mathrm{~min}, \mathrm{NS}$.
In salt-resistant patients who received ANP, mean blood pressure decreased during ANP infusion from $121 \pm 6 \mathrm{~mm} \mathrm{Hg}$ at time 0 to $112 \pm 5 \mathrm{~mm} \mathrm{Hg}$ at $20 \mathrm{~min}$, $p<0.05 ; 110 \pm 3 \mathrm{~mm} \mathrm{Hg}$ at $40 \mathrm{~min}, p<0.05 ; 105 \pm 4 \mathrm{~mm}$ $\mathrm{Hg}$ at $60 \mathrm{~min}, p<0.04$. Mean blood pressure was still decreased at $120 \mathrm{~min}(111 \pm 4 \mathrm{~mm} \mathrm{Hg}, p<0.05)$, returning to basal values after $180 \mathrm{~min}(120 \pm 4 \mathrm{~mm} \mathrm{Hg})$ and $240 \mathrm{~min}(123 \pm 6 \mathrm{~mm} \mathrm{Hg})$. Also in this subgroup heart rate increased after discontinuation of ANP from $73 \pm 3$ beats/min at time 0 and $72 \pm 9$ beats/min at $60 \mathrm{~min}$ to $102 \pm 12$ beats $/ \mathrm{min}$ at $75 \mathrm{~min}, p<0.02 ; 99 \pm 8$ beats $/ \mathrm{min}$ at $90 \mathrm{~min}, p<0.04$; and $83 \pm 4$ beats $/ \mathrm{min}$ at $120 \mathrm{~min}$, NS.

Plasma insulin and glucose. In salt-sensitive patients plasma insulin levels did not change during ANP infusion, being $54.6 \pm 31.2 \mathrm{pmol} / 1$ at time 0 , and $75.6 \pm 45.1 \mathrm{pmol} / \mathrm{l}$ at $60 \mathrm{~min}$ (NS) (Fig. 1). In contrast, after the end of ANP infusion plasma insulin increased to levels of $101.4 \pm 45.2 \mathrm{pmol} / \mathrm{l}$ at $120 \mathrm{~min}$ (NS), $105 \pm$ $42 \mathrm{pmol} / 1$ at $180 \mathrm{~min}(p<0.05)$ and $121.2 \pm 48.6 \mathrm{pmol} / 1$ at $240 \mathrm{~min}(p<0.05)$ (Fig. 1). In the same group, plasma glucose levels remained unchanged during ANP infusion, being $4.59 \pm 0.6 \mathrm{mmol} / \mathrm{l}$ and $4.86 \pm 0.73 \mathrm{mmol} / \mathrm{l}$ at 0 and $60 \mathrm{~min}$ (NS), respectively. After discontinuation of ANP, plasma glucose levels increased, reaching values of $5.61 \pm 0.92 \mathrm{mmol} / \mathrm{l}$ at $120 \mathrm{~min}(p<0.04)$, $5.97 \pm 0.67 \mathrm{mmol} / 1$ at $180 \mathrm{~min}(p<0.01)$ and $6.56 \pm$ $1.03 \mathrm{mmol} / 1$ at $240 \mathrm{~min}(p<0.01)$ (Fig. 2).

Both plasma insulin ( $p<0.01$ at $120 \mathrm{~min}, p<0.03$ at 180 and $240 \mathrm{~min})$ and glucose levels $(p<0.03$ at $120 \mathrm{~min}, p<0.02$ at $180 \mathrm{~min}, p<0.001$ at $240 \mathrm{~min}$ ) were significantly higher in salt-sensitive patients than in patients receiving placebo. 

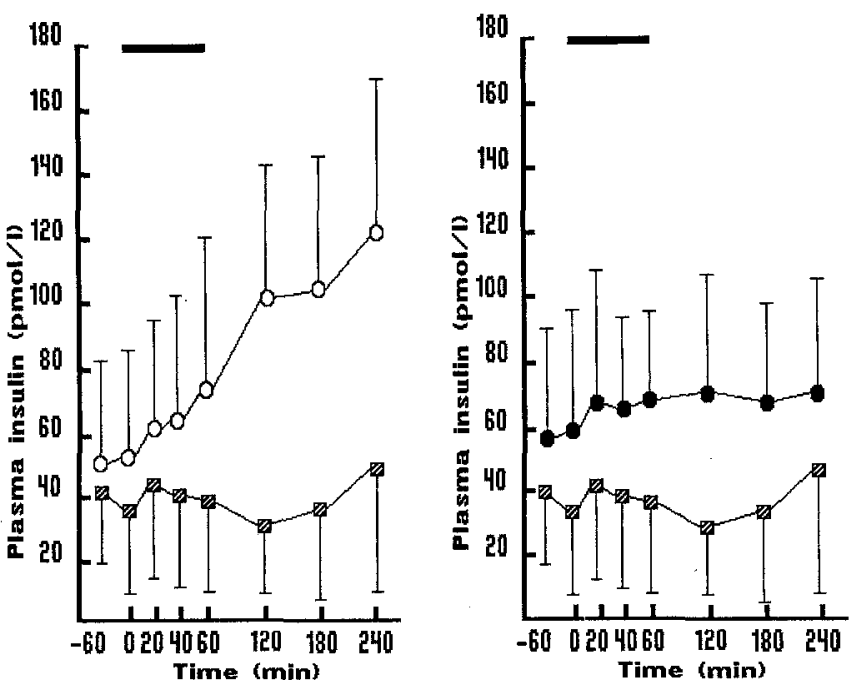

Fig. 1. Effect of ANP infusion $\left(0.04 \mu \mathrm{g} \cdot \mathrm{kg}^{-1} \cdot \mathrm{min}^{-1}\right.$ over 60 -min period) on plasma insulin levels in salt-sensitive and salt-resistant essential hypertensive patients. Plasma insulin levels resulted significantly increased only in salt-sensitive patients at time 180 and $240 \mathrm{~min}$ ( $p<0.05$ vs time 0 ). (ANP salt-sensitive, $n=8, \bigcirc ;$ ANP salt-resistant, $n=7, \bullet$; Vehicle, $n=7$, $\square-$ Horizontal bars indicate ANP infusion
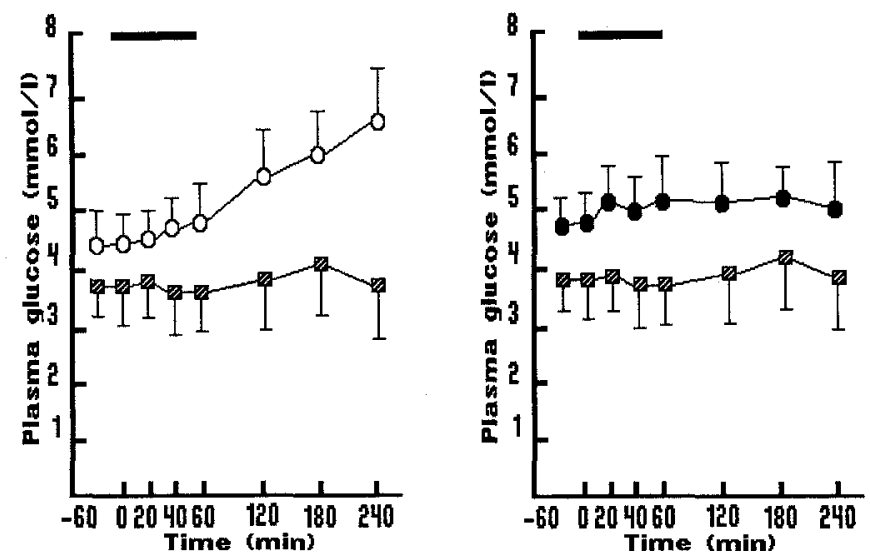

Fig. 2. Effect of ANP infusion $\left(0.04 \mu \mathrm{g} \cdot \mathrm{kg}^{-1} \cdot \mathrm{min}^{-1}\right.$ over 60 -min period) on plasma glucose levels in salt-sensitive and salt-resistant essential hypertensive patients. As compared to time 0, plasma glucose levels resulted significantly increased only in saltsensitive patients $(p<0.04$ at time $120 \mathrm{~min}, p<0.01$ at time 180 and $240 \mathrm{~min}$ ). (ANP salt-sensitive, $n=8,0-0$; ANP salt-resistant, $n=7, \bullet$; Vehicle, $n=7, \square-Z)$. Horizontal bars indicate ANPinfusion

In salt-resistant patients, no changes in plasma insulin (Fig. 1) and glucose (Fig. 2) levels were observed either during or after ANP infusion. The comparison between the salt-sensitive and the salt-resistant subgroups showed significant differences at time 120 $(p<0.05), 180(p<0.05)$, and $240 \min (p<0.04)$ for plasma insulin and at time $180(p<0.05)$ and $240 \mathrm{~min}$ $(p<0.04)$ for plasma glucose.

Serum electrolytes, urinary $\mathrm{Na}^{+}$and $\mathrm{K}^{+}$excretion. Serum $\mathrm{Na}^{+}$and $\mathrm{K}^{+}$remained constant in all patients both during and after ANP infusion. In salt-sensitive patients $\mathrm{Na}^{+}$excretion increased during ANP infusion (from $0.09 \pm 0.01 \mathrm{mmol} / \mathrm{min}$ at time 0 to $0.81 \pm 0.25$ $\mathrm{mmol} / \mathrm{min}$ at time $60 \mathrm{~min}, p<0.001$ ), was still high after discontinuation of ANP (time $180 \mathrm{~min}$ : $0.20 \pm 0.12$ $\mathrm{mmol} / \mathrm{min}, p<0.05$ ), and returned to baseline levels at time $240 \mathrm{~min}(0.16 \pm 0.09 \mathrm{mmol} / \mathrm{min}, \mathrm{NS})$. The urinary $\mathrm{K}^{+}$excretion also increased during ANP infusion (from $0.05 \pm 0.01 \mathrm{mmol} / \mathrm{min}$ at time 0 and $0.38 \pm 0.21$ $\mathrm{mmol} / \mathrm{min}$ at $60 \mathrm{~min}, p<0.05)$. In salt-resistant patients, urinary $\mathrm{Na}^{+}$excretion was $0.09 \pm 0.02 \mathrm{mmol} /$ min at time 0 , and significantly increased during ANP infusion, (time $60 \mathrm{~min}: 0.72 \pm 0.20 \mathrm{mmol} / \mathrm{min}, p<0.05$ ), while it returned to baseline levels after $120 \mathrm{~min}$ $(0.22 \pm 0.07 \mathrm{mmol} / \mathrm{min}, \mathrm{NS})$. Urinary $\mathrm{K}^{+}$excretion also increased (from $0.04 \pm 0.02 \mathrm{mmol} / \mathrm{min}$ at time 0 and $0.40 \pm 0.15 \mathrm{mmol} / \mathrm{min}$ at $60 \mathrm{~min}, p<0.05) ; \mathrm{K}^{+}$excretion returned to baseline levels in both groups at 120 min.

\section{Discussion}

As far as the relationships between insulin, salt-sensitivity, and hypertension are concerned, hyperinsulinaemia has been reported in a particular model of human salt-sensitive hypertension, the so-called "nonmodulating" essential hypertension [11]. Furthermore, obesity, NIDDM, and hypertension are often connected [12], being frequently characterized by the association of hyperinsulinaemia, insulin resistance and salt-sensitivity.

In animal models, Dahl salt-sensitive rats have higher plasma insulin levels than both Dahl salt-resistant and Sprague-Dawley rats [13]. However, during high salt intake, plasma insulin levels did not change in salt-sensitive Dahl rats, and only the blood pressure rose when they consumed an $8 \% \mathrm{NaCl}$ diet.

Rocchini et al. [14] have obtained similar data in obese normotensive adolescents, who showed higher blood pressure and insulin levels than lean control adolescents. Furthermore, blood pressure decreased after chronic salt depletion in the obese, but not in the lean adolescents [14]. The authors concluded that the blood pressure of obese adolescents is highly dependent on dietary sodium intake, and that the blood pressure sensitivity to $\mathrm{NaCl}$ may be due to hyperinsulinaemia [14]. According to this hypothesis, the prevalence of saltsensitivity is $66 \%$ in NIDDM hypertensive patients [15], and the highest levels of plasma ANP and insulin have been described in lean adult NIDDM hypertensive patients [8]. Therefore, it is intriguing to speculate that ANP, which is involved in the regulation of renal sodium excretion [16], might activate the release of insulin, a hormone which may promote renal sodium reabsorption and cause an exaggerated response to dietary salt intake [14, 17-19].

In agreement with this hypothesis, baseline levels of plasma ANP and insulin were significantly correlated 
in salt-sensitive but not in salt-resistant patients. Furthermore, we showed that the hyperinsulinaemic and hyperglycaemic response following discontinuation of ANP was present only in salt-sensitive patients.

The reasons for this phenomenon are unclear. Both the renal and the cardiac functions of our patients were normal, and the baseline ANP and insulin levels were similar in the salt-sensitive and the salt-resistant groups. Furthermore, the enhanced insulin and glucose response to ANP infusion was observed when patients were on a normal $\mathrm{NaCl}$ diet, thus the result was not dependent on individual salt intake.

Furthermore, the ANP-related changes of blood pressure, heart rate, and serum electrolytes were similar in all patients, suggesting that the enhanced insulin response to ANP infusion was not due to a peculiar sympathetic nervous system activation $[16,20]$.

Compared to salt-resistant patients, salt-sensitive patients showed a greater increase in natriuresis during ANP infusion. However, no changes in serum electrolytes occurred either during or after ANP infusion, ruling out a possible hypokalaemia-related effect on glucose uptake [17,18].

The simultaneous increase of insulin and glucose levels following discontinuation of ANP suggests an indirect action of the peptide on insulin levels. A direct stimulatory effect of ANP on insulin secretion from pancreatic beta cells should be followed by unchanged or decreased levels of plasma glucose. Therefore, it is conceivable that in salt-sensitive hypertensive patients ANP influences insulin levels by acting on other mechanisms involved in glucose uptake and/or release.

In particular, an insulin-resistant condition could explain the sustained stimulation of insulin secretion and the long lasting rise in plasma insulin levels which followed the discontinuation of ANP. However, both fasting and post-load insulin levels were normal in our patients, suggesting the presence of a normal insulin sensitivity.

In conclusion, the present findings, based on a vehicle-controlled, randomized, double-blind study, indicate that during ANP infusion there is a slight increase in plasma insulin and glucose levels in both salt-sensitive and salt-resistant essential hypertensive patients under normal sodium intake, although this was not statistically significant. Due to the small number of subjects a type II statistical error cannot be excluded. However, in salt-sensitive patients both plasma insulin and glucose levels increased after discontinuation of ANP; with levels still raised $3 \mathrm{~h}$ after the infusion. The reasons for this phenomenon are unclear, since the hyperinsulinaemic and hyperglycaemic response did not occur in salt-resistant patients. These data confirm the absence of a direct action of ANP on insulin secretion. If the rise in plasma insulin observed after ANP removal occurs under physiologic conditions, it could play some role in promoting an elevation of plasma insulin levels and the consequent enhanced blood pressure response to dietary salt intake.

\section{References}

1. Fehmann HC, Noll B, Göke R, Göke B, Trautman ME, Arnold R (1990) Atrial natriuretic factor has a weak insulinotropic action in the isolated perfused rat pancreas. Res Exp Med 190: 253-258

2. Ahren B (1988) ANF inhibits glucose-stimulated insulin secretion in mouse and rat. Am J Physiol 5: E579-E582

3. Uehlinger DE,Weidmann P, Gnadinger MP et al. (1986) Increase in circulating insulin induced by atrial natriuretic peptide in normal humans. J Cardiovasc Pharmacol 8: 1122-1129

4. Weidmann P, Gnädinger MP, Ziswiler HR et al. (1986) Cardiovascular, endocrine and renal effects of atrial natriuretic peptide in essential hypertension. J Hypertens 4[Suppl 2]: $71-83$

5. Haak T, Jungmann E, Hannappel B, Schoffling K (1990) The effect of atrial natriuretic peptide on glucose tolerance and insulin levels. Med Klin 85: 61-64

6. Ferrari P, Shaw S, Riesen W, Weidmann P (1992) Plasma insulin during physiological and pathophysiological changes in atrial natriuretic factor. Eur J Clin Pharmacol 42: 453-455

7. Ferri C, De Mattia G, Piccoli A et al. (1991) Plasma insulin levels do not change during atrial natriuretic infusion in human essential hypertensives. Am J Hypertens 4: 880-884

8. De Mattia G, Tullo O, Ferri Cet al. (1990) Atrial natriuretic factor in hypertensive diabetic patients. In: Crepaldi G, Tiengo A, Enzi G (eds) Diabetes, obesity and hyperlipidemias IV. Elsevier Science Publishers B. V.Biomedical Division, Amsterdam, pp 451-453

9. Mbanya JC, Thomas TH, Taylor R, Baylis P, Wilkinson R, Alberti KGMM (1988) Hypertension and diabetes mellitus: role of insulin and atrial natriuretic peptide. Diabetologia 31: 519 A (Abstract)

10. Sharma AM, Ruland K, Spies KP, Distler A (1991) Salt-sensitivity in young normotensive subjects is associated with hyperinsulinemic response to oral glucose. J Hypertens 9: 329-335

11. Leonetti Luparini R, Ferri C, Santucci A, Balsano F (1993) Atrial natriuretic peptide in non-modulating essential hypertension. Hypertension 21: 803-809

12. Williams RR, Hasstedt SJ, Hunt SC et al. (1991) Genetic traits related to hypertension and electrolyte metabolism. Hypertension 17[Suppl I]: I-69-I-73

13. Reaven GM, Twersky J, Chang H (1991) Abnormalities of carbohydrate and lipid metabolism in Dahl Rats. Hypertension 18: 630-635

14. Rocchini AP, Key J, Bondie D et al. (1989) The effect of weight loss on the sensitivity of blood pressure to sodium in obese adolescent. N Engl J Med 321: 580-585

15. Tuck M, Corry D, Trujillo A (1990) Salt-sensitive blood pressure and exaggerated vascular reactivity in the hypertension of diabetes mellitus. Am J Med 88: 210-216

16. Atlas SA, Laragh JH (1990) Atrial natriuretic factor: its involvement in hypertensive disorders. In: Laragh $J \mathrm{H}$, Brenner BM (eds) Hypertension: pathophysiology, diagnosis and management, Vol 1. Reaven Press, New York, pp 861-884

17. Ferrannini E, De Fronzo RA (1989) The association of hypertension, diabetes and obesity: a review. JNephrol 1:3-15

18. Santucci A, Ferri C (1992) Insulin resistance and essential hypertension: pathophysiologic and therapeutic implications. J Hypertens 10[Supp12]: S9-S15

19. Ferri C, De Mattia G, Bellini Cet al. (1993) Octreotide, a somatostatin analog, reduces insulin secretion and increases renal $\mathrm{Na}^{+}$excretion in lean essential hypertensive patients. Am J Hypertens 6: 276-281

20. Richards AM (1989) Atrial natriuretic factors administered to humans: 1984-1988. J Cardiovasc Pharmacol 13[Suppl 6]: S69-S74 